\title{
Prognostic value of mitochondrial DNA content and G10398A polymorphism in non-small cell lung cancer
}

\author{
HUI XU*', WEI HE* , HUAN-GANG JIANG, HONG ZHAO, XIAO-HONG PENG, YUE-HUA WEI, \\ JING-NI WEI, CONG-HUA XIE, CHEN LIANG, YA-HUA ZHONG, GONG ZHANG, \\ DI DENG, YUN-FENG ZHOU and FU-XIANG ZHOU
}

\begin{abstract}
Department of Radiation and Medical Oncology, Zhongnan Hospital of Wuhan University, Hubei Key Laboratory of Tumor Biological Behaviors and Hubei Cancer Clinical Study Center, Wuchang, Wuhan, Hubei 430071, P.R. China
\end{abstract}

Received July 11, 2013; Accepted September 2, 2013

DOI: $10.3892 /$ or.2013.2783

\begin{abstract}
Non-small cell lung cancer (NSCLC) is one of the leading causes of cancer-related mortality worldwide. Mitochondrial dysfunction has been postulated to render cancer cells resistant to apoptosis based on the Warburg hypothesis. However, few studies have investigated the prognostic value of mitochondrial DNA (mtDNA) content and G10398A polymorphism in NSCLC patients. mtDNA copy number and G10398A polymorphism in 128 NSCLC tissue samples were assessed by real-time PCR (RT-PCR) and PCR-RFLP respectively, and their relationship to prognosis were analyzed by survival analysis and Cox proportional hazards model. In vitro, an mtDNA deletion A549 $\mathrm{Q}^{0}$ cell model was utilized to assess the function of mtDNA on radiosensitivity. Cell cycle distribution and reactive oxygen species (ROS) were analyzed to elucidate the potential mechanisms. For the whole group, the median follow-up time and overall survival time were 22.5 and 23.4 months, respectively. Patients with high mtDNA content had a marginally longer survival time than patients with low mtDNA content $(\mathrm{P}=0.053)$. Moreover, patients with high mtDNA content plus $10398 \mathrm{G}$ had a significantly longer overall survival time compared with those having low mtDNA content plus 10398A (47 vs. 27 months, $\mathrm{P}<0.05$ ). In addition, multivariate analysis showed that stage and low mtDNA content plus 10398A were the two most independent prognostic factors. In vitro, the A549 $\mathrm{Q}^{0}$ cells showed more resistance to radiation than $\mathrm{Q}^{+}$cells. Following radiation, $\mathrm{Q}^{0}$ cells showed delayed G2 arrest and lower ROS level as compared to $\mathrm{Q}^{+}$cells. In conclusion, the present study
\end{abstract}

Correspondence to: Professor Fu-Xiang Zhou, Department of Radiation and Medical Oncology, Zhongnan Hospital of Wuhan University, 169 Donghu Road, Wuchang, Wuhan, Hubei 430071, P.R. China

E-mail: happyzfx@sina.com

${ }^{*}$ Contributed equally

Key words: mitochondrial DNA, non-small cell lung cancer, prognosis, A549 $\mathrm{Q}^{0}$ cell, radiosensitivity suggests that in patients with NSCLC, low mtDNA content plus 10398A could be a marker of poor prognosis which is associated with resistance to anticancer treatment caused by low mtDNA content plus 10398A polymorphism resulting in mitochondrial dysfunction.

\section{Introduction}

Lung cancer is one of the leading causes of cancer-related mortality worldwide and is the most frequently diagnosed cancer in men (1). The two main types of lung cancer are small cell lung cancer (SCLC) and non-small cell lung cancer (NSCLC). NSCLC accounts for $80 \%$ of lung cancer patients and has a 5-year survival rate of $<20 \%$ despite improvements in diagnosis and treatment (2). Most NSCLC patients are diagnosed at an advanced stage, in a poor performance status, and are often unresectable (3). It is crucial for improving the outcome of NSCLC to develop better molecular biomarkers for the prediction of disease progression and therapeutic resistance.

Mitochondrial dysfunction has been postulated to render cancer cells resistant to apoptosis based on the Warburg hypothesis (4). The mean copy number of mitochondrial DNA (mtDNA) in lung carcinoma tissue samples was statistically lower than that in adjacent histologically normal lung tissue samples $(\mathrm{P}<0.001)(5)$. Low copy number and low oxidative damage of mtDNA in lung cancer tissues are associated with tumor progression after neoadjuvant chemotherapy (6). In recent years, somatic mtDNA mutations including point mutation, deletion and insertion as well as decreased mtDNA copy number have been usually found in primary human cancer, including NSCLC (7). Also, 8701 and 10398 that code for ATPase6 and NADH dehydrogenase 3 were reported to be mutational hotspots in the mitochondrial genome of lung cancer (8). African-American women carrying 10398A had higher risk of invasive breast cancer (9). It has been proposed that these somatic mtDNA alterations in cancer can contribute to the switch of energy supply from mitochondrial oxidative phosphorylation to aerobic glycolysis and cancer progression (10). However, few studies have examined the prognostic value of mtDNA content and G10398A polymorphism in NSCLC patients. 
In the present study, the mtDNA copy number and 10398 genotype were assessed in tumor tissues of 128 NSCLC patients, and their prognostic values were analyzed. Furthermore, A549 cells were cultured in EB to get $\varrho^{0}$ cells. The radiosensitivity of these two cell lines $\left(\mathrm{Q}^{0}\right.$ and $\left.\mathrm{Q}^{+}\right)$were investigated. The results showed that mtDNA content and G10398A polymorphism may play a role in patient prognosis by affecting cancer cell growth. Our studies suggest that the mtDNA content and G10398A polymorphism may provide new biomarkers to predict outcome of NSCLC. Intervention of the mtDNA content and G10398A polymorphism may also represent a novel approach for cancer treatment.

\section{Materials and methods}

Samples and clinical data. A total of 128 NSCLC tissue samples were obtained from patients who underwent surgical resection (including lymph node biopsy operation) at Zhongnan Hospital of Wuhan University between July 2006 and July 2011. Clinical staging was assessed according to the American Joint Committee on Cancer (AJCC, seventh edition). None of the patients had received radiotherapy or chemotherapy prior to surgery. Formalin-fixed and paraffinembedded surgical tissue samples were collected from the Department of Pathology. Pathological diagnosis was made according to the World Health Organization 2004 scheme. The study protocol was reviewed and approved by the Institutional Review Board of Zhongnan Hospital of Wuhan University. All participants (including 95 male and 33 female patients; age range, 20-80 years) provided written informed consent to participate in this study. Clinical information, including age, gender, pathological type, tumor node metastasis (TNM) stage, smoking status, EGFR mutation status and clinical follow-up data, was recorded prospectively (Table I). In addition to the scheduled follow-up examination within 6 months, patients were followed-up at 3-month intervals for up to 2 years, then every 6 months for 5 years, and annually thereafter. For the whole group, the median follow-up time and overall survival (OS) time were 22.5 and 23.4 months, respectively; 58 patients (45.3\%) died during this period.

Tissue genomic DNA acquisition. Total DNA from formalinfixed, paraffin-embedded tissues was extracted using the E.Z.N.A. ${ }^{\circledR}$ FFPE DNA kit (Omega), according to the manufacturer's instructions. The extracted DNA was eluted in $100 \mu \mathrm{l}$ TE buffer and stored at $-20^{\circ} \mathrm{C}$.

Determination of mtDNA copy number. mtDNA content was assessed by quantification of a unique fragment in human mitochondrial genome NC_012920 region relative to a single copy region of the nuclear gene $\beta_{2} \mathrm{M}$ using a real-time PCR (RT-PCR) assay. NC_012920 forward, 5'-CTTCTGGCCACAGCACTT AAAC-3' and reverse, 5'-GCTGGTGTTAGGGTTCTTTGT TTT-3' (64 bp product); $\beta_{2} \mathrm{M}$ forward, 5'-GCTGGGTAGCT CTAAACAATGTATTCA-3' and reverse, 5'-CCATGTACTA ACAAATGTCTAAAATGGT-3' (93 bp product). RT-PCR was carried out using an $\mathrm{iQ}^{\mathrm{TM}} 5$ Multicolor Real-Time PCR Detection System (Bio-Rad) with a total volume of $25 \mu \mathrm{l}$ reaction mixture containing $100 \mathrm{ng}$ DNA template $(2 \mu \mathrm{l}), 12.5 \mu \mathrm{l}$ QuantiTect SYBR-Green PCR Master mix (Takara), and $0.5 \mu \mathrm{l}$
Table I. Patient characteristics.

\begin{tabular}{llc}
\hline Variable & Group & $\mathrm{n}(\%)$ \\
\hline Gender & Male & $95(74.2)$ \\
& Female & $33(25.8)$ \\
Age (years) & Mean & 59.4 \\
Cigarette smoking & Range & $20-80$ \\
& No & $48(37.5)$ \\
Histological status & Yes & $80(62.5)$ \\
& AC & $58(45.3)$ \\
& SCC & $52(40.6)$ \\
EGFR mutation & ASC & $15(11.7)$ \\
& LCC & $3(2.4)$ \\
Stage & No & $114(89.1)$ \\
& Yes & $14(10.9)$ \\
& I & $24(18.8)$ \\
Follow-up status & II & $26(20.3)$ \\
& III & $62(48.4)$ \\
& IV & $16(12.5)$ \\
& Survival & $70(54.7)$ \\
\hline
\end{tabular}

AC, adenocarcinoma; SCC, squamous cell carcinoma; ASC, adenosquamous carcinoma; LCC, large cell carcinoma.

of each primer, $0.5 \mu 1$ ROX Reference Dye II, $9 \mu 1 \mathrm{ddH}_{2} \mathrm{O}$. The run protocol: initial 'Hot Start' activation step for $5 \mathrm{~min}$ at $94^{\circ} \mathrm{C}$ followed by 40 cycles of $30 \mathrm{sec}$ at $94^{\circ} \mathrm{C}, 30 \mathrm{sec}$ at $60^{\circ} \mathrm{C}$, and $30 \mathrm{sec}$ at $72^{\circ} \mathrm{C}$.

Genotyping of mtDNA 10398. DNA samples were PCR-amplified using primers located between 10284-10484 np, forward, 5'-CAAACAACTAACCTGCCAC-3' and reverse primer, 5'-ATGAGGGGCATTTGGTA-3' (201 bp product), followed by digestion with $D d e \mathrm{I}$ at $37^{\circ} \mathrm{C}$. On resolving the $D d e \mathrm{I}$-digested products in a $2 \%$ agarose gel, the 10398A allele gave rise to bands of 128 and $73 \mathrm{bp}$, whereas the $10398 \mathrm{G}$ allele demonstrated bands of 90,73 and $38 \mathrm{bp}$.

Detection of EGFR mutations. PCR-RFLP was performed for mutation analysis of EGFR exons 18, 19 and 21. The mutant allele of exon 18 was not digested by the restriction enzyme ApaI due to the base substitution of $\mathrm{G}$ to $\mathrm{X}$ at the second base of GGGCCC. Since the range of exon 19 deletions containing commonly deleted codons 746 to 751 , differences in the sizes of the PCR products enabled us to distinguish mutant-type from wild-type. The restriction enzyme MscI was used to digest the TGGCCA sequence in the amplicon of the wild-type allele of exon 21. By contrast, mutant type (L858R) was not digested due to the base substitution of $\mathrm{T}$ to $\mathrm{G}$ of TGGCCA. The digested-products were run in $2 \%$ agarose gel.

Cell line and treatment. A human NSCLC cell line A549 was used in this study. $\mathrm{Q}^{0}$ cells depleted of mtDNA were 
generated by incubating wild-type cells for 18 weeks in complete medium that was additionally supplemented with $100 \mathrm{ng} / \mathrm{ml}$ ethidium bromide (Sigma), $100 \mu \mathrm{g} / \mathrm{ml}$ pyruvate and $50 \mu \mathrm{g} / \mathrm{ml}$ uridine (11). Following selection, $\mathrm{Q}^{0}$ cells were cultured in the medium specified above at $37^{\circ} \mathrm{C}$ in an incubator with $95 \%$ air and $5 \% \mathrm{CO}_{2}$ with $110 \mathrm{mg} / \mathrm{l}$ sodium pyruvate and $50 \mu \mathrm{g} / \mathrm{ml}$ uridine. To verify mtDNA depletion in $\varrho^{0}$ cells, total cellular DNA from $\varrho^{+}$and $\varrho^{0}$ cells was extracted and subjected to PCR amplification using two pairs of human mtDNA specific primers: i) COX-I F, 5'-ACACGAGCATATTTCACCTCCG-3' and COX-I R, 5'-GGATTTTGGCGTAGGTTTGGTC-3', which gave a 337 bp product; ii) mtDNA-P1 F, 5'-AACATACCCAT GGCCAACCT-3' and mtDNA-P1 R, 5'-GGCAGGAGTAAT CAGAGGTG-3', which gave a 533 bp product. As a control, we measured the expression of $\beta$-actin F, 5'-TGGAAGGAC TCATGACCACA-3' and R, 5'-TTCAGCTCAGGGATGAC CTT-3', 283 bp, which is coded by nuclear DNA.

Clonogenic survival. Cells were plated in triplicate into $60-\mathrm{mm}$ tissue culture dishes at limiting dilutions. After irradiation $(0$, $1,2,4,6,8$ and $10 \mathrm{~Gy}$ ), the cells were incubated for 2 weeks to allow colony formation. The colonies were then fixed in $70 \%$ ethanol and stained with $1 \%$ crystal violet. A colony population should contain $>50$ cells. Plating efficiencies (PEs) for untreated control cultures were calculated using the following formula: $\mathrm{PE}=$ (number of colonies counted/number of cells seeded) $x 100$. Surviving fractions (SFs) were calculated using the following formula: $\mathrm{SF}=$ (number of colonies counted) $/$ (number of cells seeded XPE).

Cell cycle analysis. $\mathrm{Q}^{+}$and $\mathrm{Q}^{0}$ cells in exponential growth were irradiated with $4 \mathrm{~Gy}$ and collected at 4, 8, 12, 16 and $24 \mathrm{~h}$. Cell cycle phase distributions were measured by flow cytometry using propidium iodide (PI). Briefly, cells were collected and fixed in suspension in $70 \%$ ethanol on ice and then stored at $4^{\circ} \mathrm{C}$. Cells were centrifuged at $500 \mathrm{~g}$, washed with $1 \mathrm{ml}$ PBS, centrifuged again, and resuspended in PBS containing $20 \mu \mathrm{g} / \mathrm{ml}$ PI and $10 \mu \mathrm{g} / \mathrm{ml}$ RNase A. After $30 \mathrm{~min}$ incubation in the dark at room temperature, PI-stained cells were analyzed for DNA content by flow cytometry, and the percentage of cells in G1, S and G2/M were calculated using MODFIT software (12).

Reactive oxygen species assay. $\mathrm{Q}^{+}$and $\mathrm{Q}^{0}$ cells in exponential growth were plated in 96-well cell culture plates. Prior to $4 \mathrm{~Gy}$ radiation, DCFH-DA was added and then incubated for $20 \mathrm{~min}$; cells were washed three times with serum-free cell culture in order to sufficiently remove DCFH-DA not up-taken by the cells. Modulus ${ }^{\mathrm{TM}}$ II Microplate was used to detect fluorescence immediately, and the value at this time was recorded as $\mathrm{ft}_{0}$, every $30 \mathrm{~min}$ afterwards, fluorescent values were denoted as $\mathrm{ft}_{30}, \mathrm{ft}_{60}, \mathrm{ft}_{90}$ and $\mathrm{ft}_{120}$. The fluorescent growth rate formula is: $\left[\left(\mathrm{ft}_{\mathrm{n}}-\mathrm{ft}_{0}\right) / \mathrm{ft}_{0}\right] \times 100 \%(13)$.

Statistical analyses. The relationships between mtDNA content, G10398A polymorphism and survival time were analyzed by the $\chi^{2}$ test. Kaplan-Meier survival curves and the log-rank test were used to analyze OS. Multivariate analysis was performed using the Cox Proportional Hazards model.

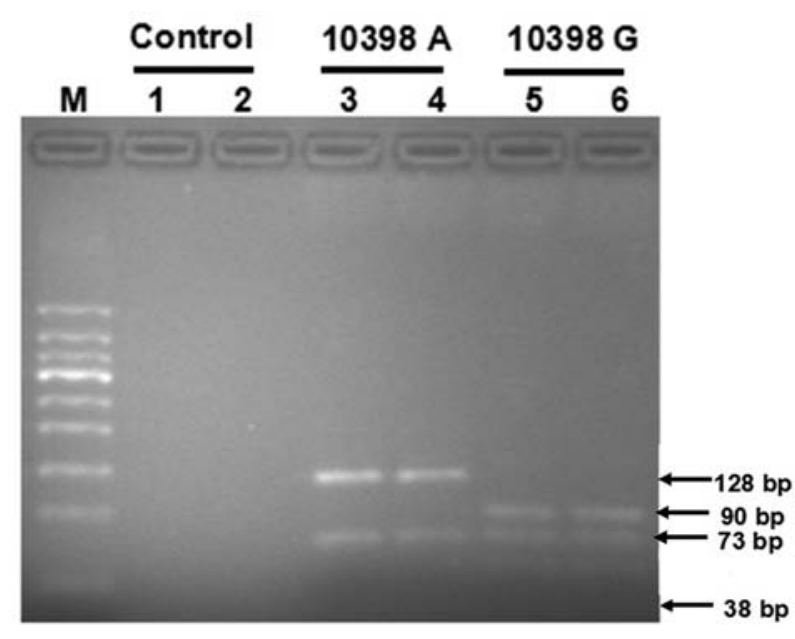

Figure 1. RFLP pattern of G10398A polymorphism. Lane M was $50 \mathrm{bp}$ DNA ladder. Banding patterns in lanes 1 and 2 were controls. Lanes 3 and 4 represent 10398A allele, which gave 73 and 128 bp. Lanes 5 and 6 represent $10398 \mathrm{G}$ allele including 90,73 and $38 \mathrm{bp}$.

\section{Results}

mtDNA content and G10398A polymorphism. The mean $\mathrm{Ct}$ values for $\beta_{2} \mathrm{M}$ sequence (representing total nDNA) and NC_012920 gene sequence (representing total mtDNA) in cancerous tissues ranged from 20.78 to 28.32 and from 12.37 to 23.15 , respectively. The mtDNA content of NSCLC tissue samples ranged from 23.75 to 1833.01 copy number. The analysis of G10398A polymorphism showed that $49.2 \%$ (63/128) was A and 50.8\% (65/128) was G (Fig. 1).

Prognostic significance of mtDNA content and G10398A polymorphism. Low mtDNA content was more common in stage III and IV than in stage I and II (71.9 vs. $28.1 \%$, respectively; $\left.\chi^{2}=6.433 ; \mathrm{P}=0.018\right)$. There was no relationship between mtDNA content and gender, age, smoking status, histology, EGFR mutation status or G10398A polymorphism (Table II). mtDNA content and G10398A polymorphism were subjected to survival analysis alone and in combination (Fig. 2). Low mtDNA content patients had a marginally shorter survival time than high mtDNA content patients (median survival time 27.9 vs. 34.1 months; $\left.\chi^{2}=3.742 ; \mathrm{P}=0.053\right)$. There was no survival difference when G10398A polymorphism was analyzed alone. However, when combining mtDNA content with G10398A polymorphism, OS in NSCLC patients with low mtDNA content plus 10398A was significantly shorter than in patients with high mtDNA content plus $10398 \mathrm{G}$ (median survival time $26.3 \mathrm{vs}$. 47.3 months; $\left.\chi^{2}=6.010 ; \mathrm{P}=0.0141\right)$. All the analyzed clinical parameters (gender, age, smoking status, histology and stage, EGFR mutation status) and mtDNA (mtDNA content, G10398A polymorphism, mtDNA content plus G10398A polymorphism) were entered into a multivariate analysis. Cox regression analysis showed that stage, low mtDNA content plus 10398A were the two most independent prognostic factors in patients with NSCLC $\left(\chi^{2}=6.235, \mathrm{P}=0.013\right.$; $\chi^{2}=18.515, \mathrm{P}<0.0005$, respectively, forward: Wald; $\mathrm{P}=0.05$, entry; $\mathrm{P}=0.10$, removal) (Table III). 
Table II. Relationships between mtDNA content and clinical parameters $(n=128)$.

\begin{tabular}{|c|c|c|c|c|c|}
\hline Variable & $\begin{array}{l}\text { Low mtDNA } \\
\text { content, n (\%) }\end{array}$ & $\begin{array}{l}\text { High mtDNA } \\
\text { content, n (\%) }\end{array}$ & $\chi^{2}$ & P-value & OR $(95 \% \mathrm{CI})$ \\
\hline Gender & & & 0.641 & 0.549 & $0.725(0.329-1.595)$ \\
\hline Male & 45 (47.4) & $50(52.6)$ & & & \\
\hline Female & $19(57.6)$ & $14(42.4)$ & & & \\
\hline Age & & & 1.846 & 0.257 & $1.871(0.752-4.655)$ \\
\hline$\leq 50$ & $15(62.5)$ & $9(37.5)$ & & & \\
\hline$>50$ & $49(47.1)$ & $55(52.9)$ & & & \\
\hline Smoking status & & & 0.533 & 0.584 & $1.306(0.637-2.677)$ \\
\hline No & $26(54.2)$ & $22(45.8)$ & & & \\
\hline Yes & $38(47.5)$ & $42(52.5)$ & & & \\
\hline Histology & & & 0.504 & 0.594 & $0.777(0.387-1.560)$ \\
\hline $\mathrm{AC}$ & $27(46.6)$ & $31(53.4)$ & & & \\
\hline Others & $37(52.9)$ & $33(47.1)$ & & & \\
\hline EGFR mutation & & & 0.321 & 0.571 & $1.381(0.450-4.234)$ \\
\hline No & $56(87.5)$ & $58(90.6)$ & & & \\
\hline Yes & $8(12.5)$ & $6(9.4)$ & & & \\
\hline Stage & & & 6.433 & 0.018 & $0.391(0.188-0.814)$ \\
\hline $\mathrm{I}+\mathrm{II}$ & $18(28.1)$ & $32(50.0)$ & & & \\
\hline III+IV & $46(71.9)$ & $32(50.0)$ & & & \\
\hline 10398 & & & 0.781 & 0.480 & $1.368(0.683-2.741)$ \\
\hline $\mathrm{A}$ & $34(54.0)$ & $29(46.0)$ & & & \\
\hline G & $30(46.2)$ & $35(53.8)$ & & & \\
\hline
\end{tabular}

The $\chi^{2}$ tests were two-sided. mtDNA, mitochondrial DNA; AC, adenocarcinoma. OR, odds ratio; CI, confidence interval.

A

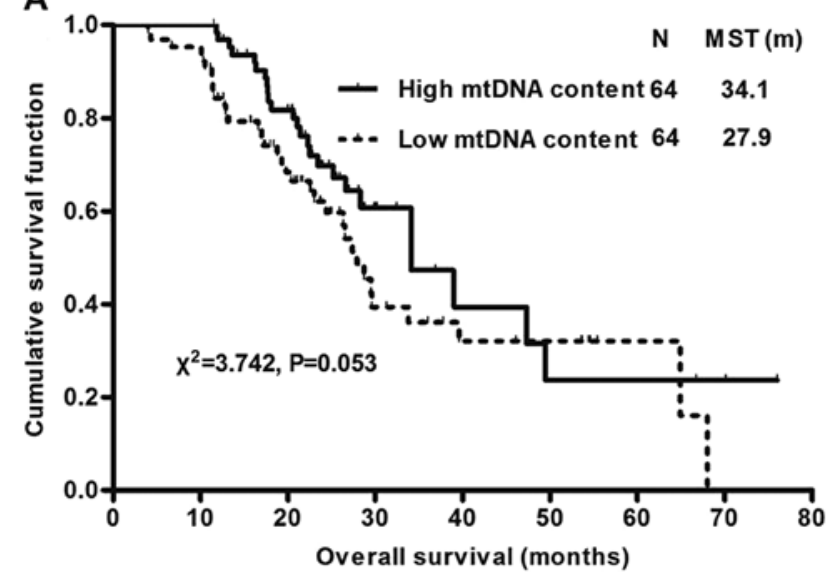

B

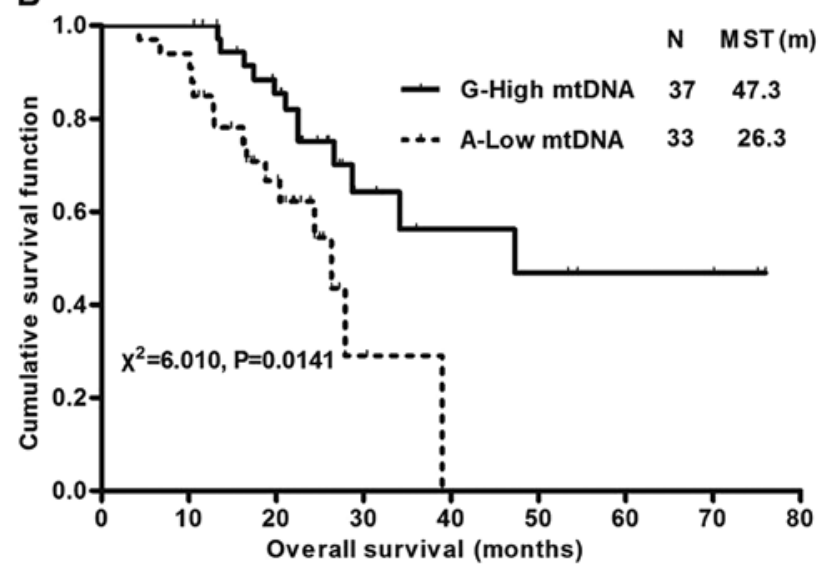

Figure 2. Survival analysis for mitochondrial DNA (mtDNA) content and G10398A polymorphism. (A) mtDNA content alone; (B) mtDNA content plus G10398A polymorphism. Overall survival time in NSCLC patients was significantly shorter in patients with low mtDNA content plus 10398A than in patients with high mtDNA content plus $10398 \mathrm{G}$ (median survival time 26.3 vs. 47.3 months; $\chi^{2}=6.010$; $\mathrm{P}=0.0141$; Kaplan-Meier analysis, log-rank test).

Generation and verification of $\varrho^{0}$ cell model. To verify the mtDNA depletion, total cellular DNA was extracted and subjected to PCR using two pairs of human mtDNA specific primers, as previously described. $\mathrm{Q}^{+}$and $\mathrm{Q}^{0}$ cells contained equivalent amounts of GAPDH, indicating that nuclear DNA was similar between the cell lines. However, $\varrho^{+}$cells contained
mtDNA, while $\mathrm{Q}^{0}$ cells contained no mtDNA (Fig. 3A). The growth defects experiment found growth inhibition in $\mathrm{Q}^{0}$ cells when the culture medium lacked sodium pyruvate and uridine. $\mathrm{Q}^{0}$ cells continued to proliferate at a slower speed in the complete medium containing sodium pyruvate and uridine (Fig. 3B). 
Table III. Multivariate analysis of overall survival.

\begin{tabular}{lrrrc}
\hline Variable & Wald & P-value & OR & $95 \%$ CI \\
\hline Stage & 6.235 & 0.013 & 2.186 & $1.152-4.147$ \\
mtDNA plus AG & 18.515 & 0.000 & 0.392 & $0.256-0.601$ \\
\hline
\end{tabular}

Cox regression analysis, forward: Wald; $\mathrm{P}=0.05$, entry; $\mathrm{P}=0.10$, removal. OR, odds ratio; CI, confidence interval.
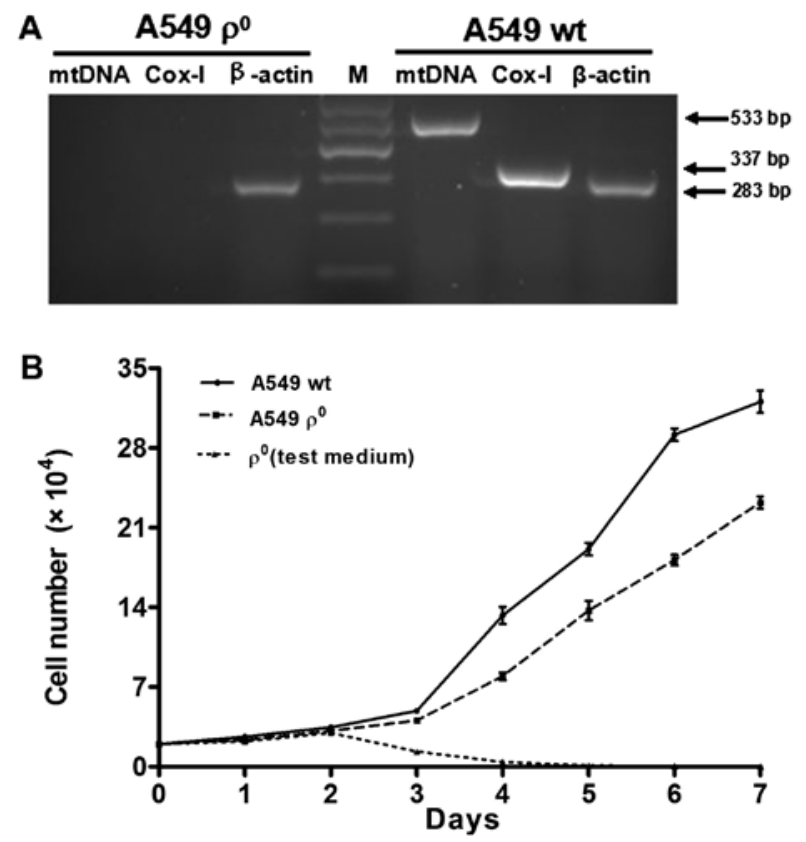

Figure 3. Generation and verification of $\mathrm{Q}^{0}$ Cells. (A) Mitochondrial DNA (mtDNA) and $\beta$-actin gene were amplified by PCR. The PCR products were visualized on $2 \%$ agarose gel by $\mathrm{EtBr}$ staining, showing the absence of mitochondrial genome in $\mathrm{Q}^{0}$ cells. (B) $\mathrm{Q}^{0}$ cells exhibited profoundly delayed growth kinetics compared to their parental cells.

Mitochondrial dysfunction results in radioresistance in human NSCLC cells. Colony formation assay was used to evaluate the radiosensitivity of A549 $\mathrm{Q}^{0}$ and $\mathrm{Q}^{+}$cells. A549 $\mathrm{Q}^{0}$ and $\mathrm{Q}^{+}$cells were treated with different doses of $\mathrm{X}$-ray irradiation, and the cloning efficiency (PE) and survival fraction (SF) were calculated. The linear-quadratic model was used to fit the survival curves (Fig. 4). Surviving fraction of cells after irradiation in $2 \mathrm{~Gy}\left(\mathrm{SF}_{2}\right)$ was $0.675 \pm 0.013$ and $0.492 \pm 0.022$ $(\mathrm{P}<0.01)$, suggesting that mtDNA deletion induced radioresistance of A549 cells.

mtDNA depletion suppresses radiation-induced $G 2$ checkpoint activation in human NSCLC cells. Cell cycle analysis showed that both $\varrho^{0}$ and $\varrho^{+}$cells showed $\mathrm{G} 2$ arrest after 4 Gy radiation, but the $\mathrm{G} 2$ arrest in $\mathrm{Q}^{0}$ cells was inferior to $\mathrm{Q}^{+}$cells (39.55 $\pm 0.50 \%$ vs. $48.08 \pm 2.92 \%, \mathrm{P}<0.01)$. The A549 $\mathrm{Q}^{+}$cell G2 arrest peak appeared at $12 \mathrm{~h}$ after irradiation, while the A549 $\mathrm{Q}^{0}$ cell appeared at $16 \mathrm{~h}$ (Fig. 5); S and G1 phase changes had no significant difference.

mtDNA depletion suppresses radiation-induced reactive oxygen species (ROS) production in human NSCLC cells.

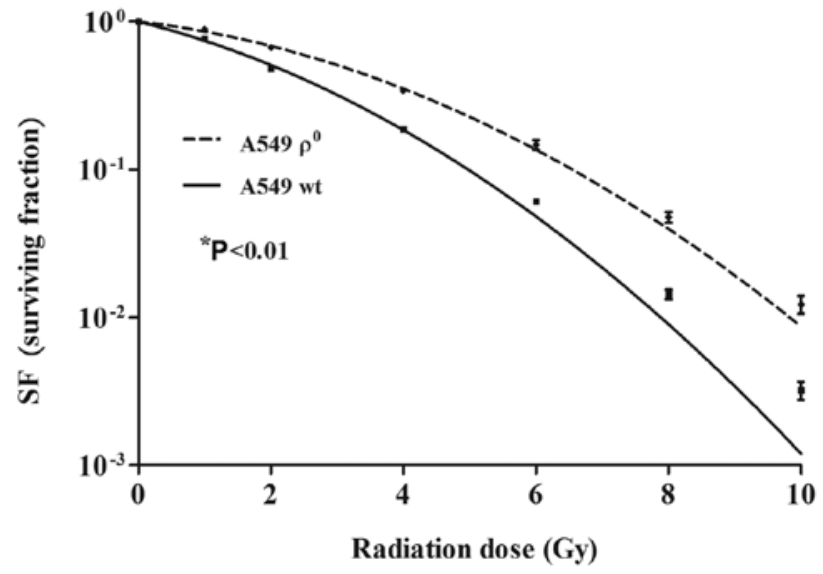

Figure 4. The cell survival curve of A549 $\varrho^{0}$ and $\varrho^{+}$cells. Cells were irradiated with $0,1,2,4,6,8$ and $10 \mathrm{~Gy}$, and then plated for colony formation for 2 weeks.

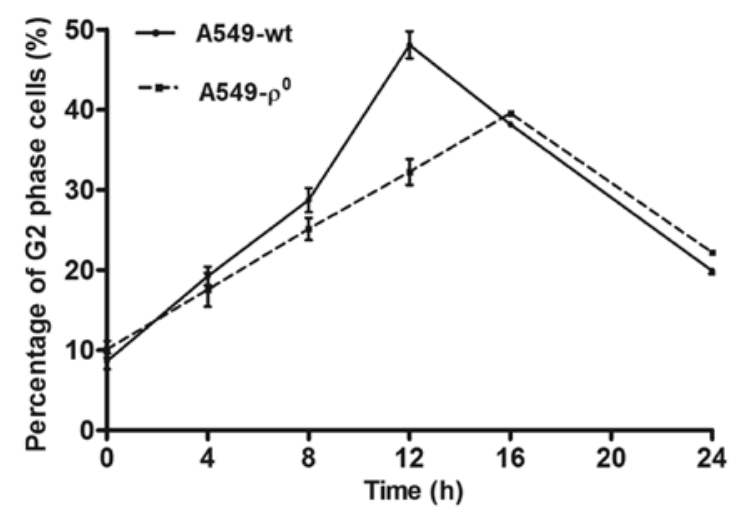

Figure 5. The change of G2 phase in A549 $\mathrm{Q}^{0}$ and $\mathrm{Q}^{+}$cells after 4 Gy irradiation. After radiation, $Q^{0}$ cells showed delayed $\mathrm{G} 2$ arrest.

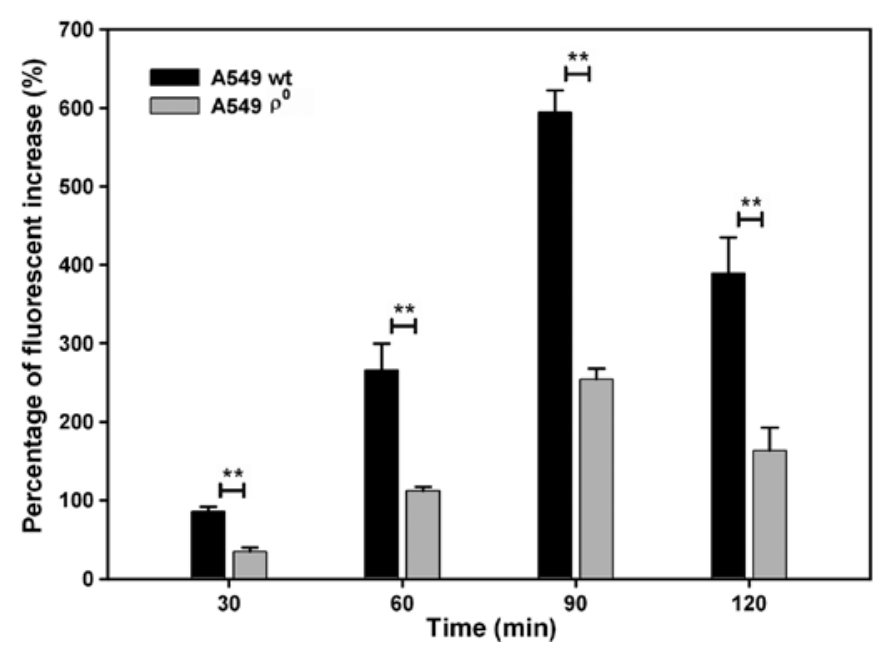

Figure 6. The change of reactive oxygen species (ROS) level after irradiation in $\mathrm{A} 549 \mathrm{Q}^{0}$ and $\mathrm{Q}^{+}$cells after $4 \mathrm{~Gy}$ irradiation. The ROS level of $\mathrm{Q}^{0}$ cells was significantly less than $\mathrm{Q}^{+}$cells. ${ }^{* *} \mathrm{P}<0.01$.

The ROS levels of $\mathrm{Q}^{0}$ cells were significantly less than $\mathrm{Q}^{+}$ cells. The rate of fluorescence increase $(\%)$ improved after the 4 Gy radiation exposure and peaked at 90 min both in $\varrho^{0}$ and $\mathrm{Q}^{+}$cells $(254.17 \pm 13.65 \%$ vs. $594.28 \pm 38.22 \%, \mathrm{P}<0.01)$ (Fig. 6). 


\section{Discussion}

Mitochondria are important and semi-autonomous organelles in eukaryotic cells. Each mitochondrion contains 2-10 copies of its genome. The copy number of mtDNA in each cell varies with cell type. In addition to plenty of somatic mutations in mtDNA, the increase or reduction of mtDNA copy number has been increasingly reported in a variety of primary human cancers, underscoring that accumulation of mtDNA alterations may be a pivotal factor in cancer pathogenesis and progression (14).

Previous studies indicated the potential involvement of both mutations and alteration of mtDNA content in the tumorigenesis of several malignancies (15). For instance, mtDNA content in patient tissues has been found to be increased in head and neck as well as in ovary cancer (8), but decreased in hepatocellular carcinoma (HCC) (16), renal cell carcinoma (RCC) (17) and advanced gastric cancer (18). These results highly suggested that the role of mtDNA in human cancer was cancer site-specific. A case-control study including 260 RCC patients and 281 matched control subjects showed that low mtDNA content was associated with a significantly increased risk of RCC (OR, 1.53; 95\% CI, 1.07-2.19) (19).

Furthermore, mtDNA content was also found to be related to patient prognosis. After an anthracycline-based regimen, the disease-free survival time of breast cancer patients with higher mtDNA content was significantly shorter than that of patients with lower mtDNA content $(\mathrm{P}=0.03)(20)$. Patients with HCC harboring lower mtDNA quantity reportedly tended to have poorer prognosis and shorter 5-year overall survival (OS) rates in comparison with the cases with higher mtDNA quantity (13). Similarly, the decline in mtDNA levels was more prevalently identified in the ulcerated and in filtrating type (Borrmann's type III) and diffusely thick type (Borrmann's type IV) of gastric carcinoma, both of which are more likely to have adverse post-operational outcome (21).

For NSCLC, Wang et al (17) found that the mean copy number of mtDNA in lung carcinoma tissue samples was statistically lower than that in adjacent histologically normal lung tissue samples. Lin et al (7) reported that decreased relative value of mtDNA copy number was linked to the advancement of tumor progression. Similarly, our results revealed that patients with low mtDNA content had a marginally shorter survival time than those with high mtDNA content. The reason may be the small sample size of our study.

mtDNA content as well as mtDNA mutations have been reported to be potentially involved in cancer; 8701 and 10398 that code for ATPase6 and NADH dehydrogenase 3 were reported to be mutational hotspots in the mitochondrial genome of lung cancer. The mtDNA G10398A polymorphism alters the structure of Complex I in the mitochondrial electron transport chain, an important site of free radical production. This polymorphism is associated with several neurodegenerative disorders. American women with the 10398A allele had a significantly increased risk of invasive breast cancer (22). In addition, mtDNA G10398A variant in African-American women with breast cancer provides resistance to apoptosis and promotes metastasis in mice (23). However, the relationship between G10398A polymorphism and NSCLC prognosis has not been reported. In this study, in NSCLC patients with high
mtDNA content plus $10398 \mathrm{G}$, OS increased by $79.8 \%$ and death risk decreased compared to patients with low mtDNA content plus 10398A (median survival time 47.3 vs. 26.3 months; $\chi^{2}=6.010 ; \mathrm{P}=0.0141 ; \mathrm{OR}, 0.392,95 \%$ CI, 0.256-0.601).

To explore the possible mechanism of mtDNA influence on the prognosis of NSCLC, $\varrho^{0}$ cell model was established by long-term exposure to low concentration of ethidium bromide. Our results showed that the A549 $\mathrm{Q}^{0}$ cells showed more resistance to radiation than $\mathrm{Q}^{+}$cells. Upon irradiation, $\mathrm{Q}^{0}$ cells showed delayed G2 arrest and decreased ability to recover from the $\mathrm{G} 2$ checkpoint compared to $\mathrm{Q}^{+}$cells. Moreover, loss of mtDNA inhibited cell growth and reduced the level of ROS (24). Recently, a growing body of functional experiments suggested that mtDNA content variations have enough capability to affect several aspects of malignant cell behaviors, such as anticancer drug sensitivity, cell growth, apoptosis as well as their invasive and metastatic potentials (14). Disruption of mtDNA integrity has been demonstrated to significantly influence cancer cell proliferation both in vitro and in vivo. For instance, mtDNA-depleted leukemia MOLT- $4 \mathrm{Q}^{0}$ cells grew markedly slower than their respective parental cells, probably due to reduced ROS generation (25). Similarly, researchers have shown that mtDNA loss considerably decreased proliferative rate and inhibited anchorage-independent growth and in vivo tumorigenicity of T47D breast cancer cells (26).

mtDNA copy number alterations have been revealed to facilitate cancer cells in acquiring resistance to a number of antitumor chemotherapeutic agents and radiation. SK-Hep1 hepatoma cells lacking mtDNA exhibited markedly reduced apoptotic death when exposed to doxorubicin and two other oxidative stressors, menadione and paraquat (27). mtDNA depletion of human pancreatic tumor cells (MiaPaCa-2) suppressed radiation-induced G2 checkpoint activation, which was accompanied by increases in both cyclin B1 and CDK1, resulted in radioresistance (28). However, Kawamura (29) reported that $\mathrm{Q}^{+}$cells were more resistant to irradiation than $\mathrm{Q}^{0}$ cells. The p53 status of the cell lines used were different, Kulawiec et al (30) reported that p53 could regulate mtDNA copy number and mitocheckpoint pathway, which may explain the different results.

In conclusion, our results highlight the complex relationships between mtDNA copy number and G10398A mutation in the prognosis of patients with NSCLC. There was no relationship between mtDNA content and gender, age, smoking status, histology, EGFR mutation status or G10398A polymorphism. Thus, other interfering prognostic factors in this paper have been eliminated. Low mtDNA content plus 10398A could be a marker of poor prognosis in NSCLC. mtDNA copy number decrease and 10398 mutation may lead to mitochondrial dysfunction, thereby influencing biological behaviors and the sensitivity to anticancer treatment so as to result in the poor prognosis. The pitfall of this study is its small sample size. Therefore, further research is required to verify the prognostic value of mtDNA copy number and G10398A polymorphism.

\section{Acknowledgements}

This study was sponsored by the National Natural Science Foundation of China (no. 81172129). The authors thank Dr Gui-Fang Yang and You Wang for their support in pathology. 


\section{References}

1. Jemal A, Bray F, Center MM, Ferlay J, Ward E and Forman D: Global cancer statistics. CA Cancer J Clin 61: 69-90, 2010

2. Siegel R, Ward E, Brawley O and Jemal A: Cancer statistics, 2011: the impact of eliminating socioeconomic and racial disparities on premature cancer deaths. CA Cancer J Clin 61: 212-236, 2011.

3. Peng J, Yang LX, Zhao XY, Gao ZQ, Yang J, et al: VCP gene variation predicts outcome of advanced non-small-cell lung cancer platinum-based chemotherapy. Tumour Biol 34: 953-961, 2013.

4. Sánchez-Aragó M, Chamorro M and Cuezva JM: Selection of cancer cells with repressed mitochondria triggers colon cancer progression. Carcinogenesis 31: 567-576, 2010.

5. Chatterjee A, Dasgupta S and Sidransky D: Mitochondrial subversion in cancer. Cancer Prev Res (Phila) 4: 638-654, 2011.

6. Wang $\mathrm{H}$ and Dai J: Changes on mitochondrial DNA content in non-small cell lung cancer. Zhongguo Fei Ai Za Zhi 14: 141-145, 2011 (In Chinese)

7. Lin CS, Wang LS, Tsai CM and Wei YH: Low copy number and low oxidative damage of mitochondrial DNA are associated with tumor progression in lung cancer tissues after neoadjuvant chemotherapy. Interact Cardiovasc Thorac Surg 7: 954-958, 2008.

8. Choi SJ, Kim SH, Kang HY, Lee J, Bhak JH, et al: Mutational hotspots in the mitochondrial genome of lung cancer. Biochem Biophys Res Commun 407: 23-27, 2011.

9. Pezzotti A, Kraft P, Hankinson SE, Hunter DJ, Buring J and Cox DG: The mitochondrial A10398G polymorphism, interaction with alcohol consumption, and breast cancer risk. PloS One 4: e5356, 2009.

10. Jin X, Zhang J, Gao Y, Ding K, Wang N, et al: Relationship between mitochondrial DNA mutations and clinical characteristics in human lung cancer. Mitochondrion 7: 347-353, 2007.

11. Malik AN, Shahni R, Rodriguez-de-Ledesma A, Laftah A and Cunningham P: Mitochondrial DNA as a non-invasive biomarker: accurate quantification using real time quantitative PCR without co-amplification of pseudogenes and dilution bias Biochem Biophys Res Commun 412: 1-7, 2011.

12. Kawada I, Soejima K, Watanabe H, Nakachi I, Yasuda H, et al: An alternative method for screening EGFR mutation using RFLP in non-small cell lung cancer patients. J Thorac Oncol 3: 1096-1103, 2007.

13. Datta S, Majumder M, Biswas NK, Sikdar N and Roy B: Increased risk of oral cancer in relation to common Indian mitochondrial polymorphisms and Autosomal GSTP1 locus. Cancer 110: 1991-1999, 2007.

14. Yu M: Generation, function and diagnostic value of mitochondrial DNA copy number alterations in human cancers. Life Sci 89: 65-71, 2011.

15. Yu M: Somatic mitochondrial DNA mutations in human cancers. Adv Clin Chem 57: 99-138, 2012.

16. Kim MM, Clinger JD, Masayesva BG, Ha PK, Zahurak ML, et al: Mitochondrial DNA quantity increases with histopathologic grade in premalignant and malignant head and neck lesions. Clin Cancer Res 10: 8512-8515, 2004.
17. Wang Y, Liu VW, Xue WC, Cheung AN and Ngan HY: Association of decreased mitochondrial DNA content with ovarian cancer progression. Br J Cancer 95: 1087-1091, 2006.

18. Yamada S, Nomoto S, Fujii T, Kaneko T, Takeda S, et al: Correlation between copy number of mitochondrial DNA and clinico-pathologic parameters of hepatocellular carcinoma. Eur J Surg Oncol 32: 303-307, 2006.

19. Xing J, Chen M, Wood CG, Lin J, Spitz MR, et al: Mitochondrial DNA content: its genetic heritability and association with renal cell carcinoma. J Natl Cancer Inst 100: 1104-1112, 2008.

20. Hsu CW, Yin PH, Lee HC, Chi CW and Tseng LM: Mitochondrial DNA content as a potential marker to predict response to anthracycline in breast cancer patients. Breast J 16: 264-270, 2010.

21. Wu CW, Yin PH, Hung WY, Li AF, Li SH, et al: Mitochondrial DNA mutations and mitochondrial DNA depletion in gastric cancer. Genes Chromosomes Cancer 44: 19-28, 2005.

22. Canter JA, Kallianpur AR, Parl FF and Millikan RC: Mitochondrial DNA G10398A polymorphism and invasive breast cancer in African-American women. Cancer Res 65: 8028-8033, 2005.

23. Kulawiec M, Owens KM and Singh KK: mtDNA G10398A variant in African-American women with breast cancer provides resistance to apoptosis and promotes metastasis in mice. J Hum Genet 54: 647-654, 2009.

24. Anoopkumar-Dukie S, Conere T, Sisk GD and Allshire A: Mitochondrial modulation of oxygen-dependent radiosensitivity in some human tumour cell lines. Br J Radiol 82: 847-854, 2009.

25. Armand R, Channon JY, Kintner J, White KA, Miselis KA, et al: The effects of ethidium bromide induced loss of mitochondrial DNA on mitochondrial phenotype and ultrastructure in a human leukemia T-cell line (MOLT-4 cells). Toxicol Appl Pharmacol 196: 68-79, 2004

26. Yu M, Shi Y, Wei X, Yang Y, Zhou Y, et al: Depletion of mitochondrial DNA by ethidium bromide treatment inhibits the proliferation and tumorigenesis of T47D human breast cancer cells. Toxicol Lett 170: 83-93, 2007.

27. Park SY, Chang I, Kim JY, Kang SW, Park SH, et al: Resistance of mitochondrial DNA-depleted cells against cell death: role of mitochondrial superoxide dismutase. J Biol Chem 279: 7512-7520, 2004

28. Cloos CR, Daniels DH, Kalen A, Matthews K, Du J, et al: Mitochondrial DNA depletion induces radioresistance by suppressing G2 checkpoint activation in human pancreatic cancer cells. Radiat Res 171: 581-587, 2009.

29. Kawamura SD, Takai K and Watanabe J, Hayashi J, Hayakawa K and Akashi M: Role of mitochondrial DNA in cells exposed to irradiation: generation of reactive oxygen species (ROS) is required for G2 checkpoint upon irradiation. J Health Sci 51: 385-393, 2005

30. Kulawiec M, Ayyasamy V and Singh KK: p53 regulates mtDNA copy number and mitocheckpoint pathway. J Carcinog 8: 8, 2009. 